\title{
Occupational therapists' views and perceptions of functional capacity evaluations of employees suffering from major depressive disorders
}

\author{
Enos Ramano, BOccTher (Medunsa), Dip Voc Rehab (Pret), MOccTher (Pret), PhD (Pret), CAMAG \\ (ABIME)
}

Part-time lecturer Department of Occupational Therapy, School of Health Care Sciences, Faculty of Health Sciences, University of Pretoria and full time Private Practitioner.

\section{Tania Buys, BOccTher (UFS), BOccTher (Hons) (Pret), MOccTher (Pret)}

Lecturer Department of Occupational Therapy, School of Health Care Sciences, Faculty of Health Sciences, University of Pretoria.

Introduction: Major depressive disorders (MDD) cause work disability and work loss, often resulting in unemployment. Employees with MDD are often referred to occupational therapists (OTs) to assist with functional capacity evaluation (FCE). Functional Capacity Evaluation forms a part of the return-to-work decision making process. This study describes the views and perceptions of occupational therapists regarding the requirements needed to conduct reliable FCEs of employees suffering from MDD.

Methods: This study employed a descriptive, qualitative study design. Data were collected in three phases using open-ended questions, focus groups and member checking groups. Thematic content data analysis was used.

Findings: In total, 78 occupational therapists were recruited and 39 participated, with response rates of (28) $47 \%,(I I) 61 \%$ and (9) $82 \%$ respectively across the three phases. Nine participants took part in the focus groups and member checking groups. Three themes emerged, namely: (I) occupational therapists' competencies in performing functional capacity evaluations (2) the process of functional capacity evaluation and (3) comprehensive functional capacity evaluation.

Conclusion: The views and perceptions of occupational therapists of performing FCEs is to formulate return-to-work decisions. Occupational therapists should be competent in the use of standardised measurement tools, non-standardised assessment and clinical reasoning.

Key words: Major Depressive Disorder, Functional Capacity Evaluation, occupational therapy, return-to-work, vocational rehabilitation

\section{INTRODUCTION}

Major depressive disorder (MDD) is considered the leading cause of disability in the world as measured by years living with a disability (YLD) ${ }^{1,2}$. Living with a disability implies working with a disability. Unrecognised and untreated MDD leads to high rates of absenteeism and presenteeism, which can cause reduced productivity and strained interpersonal relationships in the workplace as well as financial losses for employers ${ }^{2}$. South Africa experiences an estimated total of R3.6 billion in loss of earnings as a result of MDD². Recent studies by Stander et al. ${ }^{2}$ and Welthagen and Els $s^{3}$ have revealed that almost $30 \%$ of South African workers have experienced diagnosed depression episodes which significantly reduced their performance and productivity. Recurrent major depressive disorder is associated with prolonged work disability and job loss ${ }^{4}$. Treating depression and performing accurate functional capacity evaluations (FCEs) when making return-to-work decisions can enhance treatment outcomes and reduce future financial losses for employers ${ }^{4,5}$.

Employees with MDD are often referred to occupational therapists to assist with FCEs. Through the process of FCEs, the physical, mental and functional level of work that an employee can perform is established. The results of FCEs determine whether an employee can perform work-related tasks after being diagnosed with an illness such as MDD ${ }^{5}$. Functional capacity evaluations can therefore indicate modifications to the employees' work-station or work place ${ }^{6}$. Occupational therapists can assist employers by determining if employees are temporarily or permanently unable to work by carrying out FCEs, and by recommending appropriate reasonable accommodations aligned with the relevant legislative provisions.
Globally occupational therapists have no clear guidelines or processes for conducting FCEs for employees suffering from MDD. Instead, occupational therapists practising in mental health use a range of standardised measurements ${ }^{7,8}$ to ensure quality in their evaluations and to justify their objective assessment findings. In Canada, most occupational therapists measure global functioning using the Canadian Occupational Performance Measure ${ }^{9}$, although an assessment of motor and process skills would have been more desirable ${ }^{10}$. Non-standardised assessments that include interviews and task-based assessments have also been used to evaluate mental health patients ${ }^{10}$. The exclusive use of non-standardised assessments however, restricts the evaluation of occupational therapists in mental health.

South African occupational therapists have developed their own unpublished FCE formats for evaluating employees with MDD in their clinical practices. This type of practice has led to a lack of clinical evidence for performance-based occupational therapy assessments in the mental health field ". Aside from testing measurable instruments for assessing mental health, the occupational therapy profession needs to develop assessments that link mental health with the activities of daily living more effectively ${ }^{12}$. Anecdotally it appears that the variability of FCEs done in South Africa may be perpetuated by a lack of resources for training and acquisition of appropriate standardised measurement tools. Similar reasons were supplied by Canadian occupational therapists for not adopting more standardised tests in their assessments ${ }^{10}$. Without proper training, personal commitment and specific guidelines for FCE's, occupational therapists may struggle to interpret and integrate different standardised measures into their practices. 
Major depressive disorders is a risk factor for work disability ${ }^{13}$, especially in South Africa, where poverty ${ }^{14}$, stressful work conditions $^{3}$ and the advanced age of the work-force all contribute to a feeling of hopelessness ${ }^{3,15}$. The occupational therapist's experience of making return-to-work decisions is influenced by the employee being assessed, by the employers' requirements, and ultimately by the weight of making a decision that may have permanent consequences for the employee ${ }^{16}$. In this study the views of occupational therapists regarding FCE for employees suffering from MDD are described, including determining the perceptions of occupational therapists regarding professional competency and test comprehensiveness. It is the intention of the researchers that this study will influence occupational therapy practices towards a standard procedure, thus enhancing the future integrity of occupational therapy as a profession and contributing towards evidence-based practice.

\section{LITERATURE REVIEW}

Major depressive disorders are diagnosed symptomatically, taking the nature, quality and duration of symptoms into account ${ }^{17}$. Essentially, depressive disorders have two main elements: low mood and anhedonia ${ }^{18,19}$. Depression leads to occupational imbalances and limitations in activity participation. Depression is recognised when the person's enjoyment of activity and activity patterns is suppressed, ${ }^{20}$ the consequences of which negatively influence the performance of daily occupations ${ }^{21}$. Furthermore, MDD leads to high rates of absenteeism and presenteeism, reduced work productivity and strained interpersonal relationships in the work place ${ }^{2,3,4}$. Therefore, there is a definite need for occupational therapists to evaluate and address the occupational dysfunction of employees who struggle with MDD.

South Africa has various laws and policies protecting and promoting the rights of people with a disability in the work-place ${ }^{22}$. The provision of the Code of Good Practice: Dismissal (CGP:D) contained as Schedule 8 of the Labour Relations Act $^{23}$ implies that employers who have employees that suffer from MDD, will need to refer those employees to mental health care practitioners (including occupational therapists) in order to evaluate the extent of such employees' incapacity to work. Although the Labour Relations $\mathrm{Act}^{23}$ does not specifically refer to disability, but rather incapacity, it encourages fair labour practices and non-discrimination in the work place.

The Employment Equity $\mathrm{Act}^{24}$ stipulates that if an employee had been ill or been injured and is unable to perform the job, the employer may request the employee to complete a functional determination of disability. Appropriate tests should then be used to determine if the employee can safely perform the job and to identify the reasonable accommodations required for the employee to perform his/her work ${ }^{24}$. Occupational therapists are probably the most relevant and experienced ${ }^{8}$ health care practitioners to assist the employer in fulfilling the provisions of both the Labour Relations $\mathrm{Act}^{23}$ and the Employment Equity $\mathrm{Act}^{24}$ by conducting FCEs.

FCEs are equated with both the objective and subjective quantification of work disability ${ }^{25}$. Furthermore, occupational therapists should select and conduct work-related assessments that demonstrate best practice. Occupational therapists also need to identify assessment tools that are considered excellent ${ }^{22}$ in terms of reliability $^{26,27}$, validity ${ }^{26,27}$, safety ${ }^{26,27}$, usefulness (utility) ${ }^{27}$, practicality ${ }^{26,27}$, sensitivity ${ }^{28}$ and objectivity ${ }^{28}$. Practice guidelines for conducting FCEs comment on the need for accuracy, comprehensiveness, objectivity, consistency, relevance, reproducibility, clinical utility/usefulness, generalisability, ecological and clinical validity, flexibility and standardised techniques and protocols ${ }^{26}$. Occupational therapists have long been proponents of functionally orientated assessments of capacity for work ${ }^{8}$.

Multiple methods, including standardised and non-standardised methods, are all used for triangulation and comparison of information $^{21}$. The evaluation should cover the work capacity of the worker in relation to a specific job or accepted occupational standard ${ }^{29}$.
Occupational therapists work with psychiatrists and psychologists, amongst others, in addressing those issues that affect the work capacity of employees suffering from $M D^{30}$. As part of a treatment team, they play a key role in facilitating return to work of employees with MDD. Although returning to work may assist with the employee's recovery ${ }^{31}$, advanced age and long periods of depression may eventually result in permanent disability ${ }^{32,33}$.

\section{RESEARCH METHODOLOGY}

\section{Study Design}

A qualitative descriptive study design was employed that allowed the researchers to provide a comprehensive deeper meaning of occupational therapists' views and perceptions about FCEs ${ }^{34}$. Data were collected in three consecutive phases as described below:

\section{Study Population}

Occupational therapists registered with the Health Professions Council of South Africa (HPCSA) were recruited for this study. The study was conducted in three phases. Participants for Phase I were recruited from a database of occupational therapy graduates who completed the Postgraduate Diploma in Vocational Rehabilitation (DVR) at the University of Pretoria (UP), this being the only South African university offering this type of qualification. Sixty-nine graduates completed this biannual programme between 1998 and 2006.

Participants for Phase II and Phase III included occupational therapists who had more than ten years' clinical experience, had obtained postgraduate qualifications in the field of occupational therapy and who worked in the field of vocational rehabilitation $(\mathrm{VR})$ and/or mental health $(\mathrm{MH})$ at the time of the study.

\section{Ethical clearance and considerations}

Ethical approval was obtained from the Health Sciences Research Ethics Committee (Ethical clearance number: S34/2007) at the University of Pretoria where the study was conducted.

Permission was obtained from the Head of the Department of Occupational Therapy, University of Pretoria, to access the database of the previous vocational rehabilitation graduates for Phase I.

Each participant received an information letter to participate in the research, and written consent was obtained prior to his or her involvement in the study during each of the phases. All the copies of the informed consent forms were securely and confidentially kept.

\section{Sampling strategy}

Non-random, purposive sampling ${ }^{35,36}$ was used. Researchers strategically identified and selected knowledgeable, expert participants in all the phases. Participants had to articulate and explain their views about and their perceptions of FCE to the researchers. The sample of convenience ${ }^{36}$ was used during the focus group interview in Phase II because the researchers selected occupational therapists practicing in Gauteng since they were readily available for the focus group.

\section{Data collection procedure}

Data were collected in three consecutive phases:

\section{Phase I}

A questionnaire consisting of descriptive, open-ended questions enquiring about the occupational therapists' views and perceptions of the FCE process was posted to 60 occupational therapists in return stamped envelopes. Additionally, e-mails were sent to the same recipients as reminders.

Descriptive open-ended questions were used to encourage participants to write about their individual situations ${ }^{34,36}$ in their day to day clinical practice. See Box I on page II for the open-ended questions in Phase I. 


\section{Box I: Open-ended questions for Phase I}

What is your general understanding of functional capacity evaluation as it relates to major depressive disorder (MDD)?

When will you consider an employee with MDD to be incapable of working?

What formal and informal methods of evaluation do you use to evaluate the functional capacity of employees with MDD?

What are the reasons for using these methods or tools for employees with MDD?

Please elaborate on the areas where you feel occupational therapists have difficulties in the determination of functional capacity.

What would you advise other occupational therapists to be aware of or take into consideration when assessing employees with MDD?
Table I: Participants response rate

\begin{tabular}{|c|c|c|c|c|c|c|c|}
\hline \multirow[t]{2}{*}{ Phases } & \multirow{2}{*}{$\begin{array}{l}\text { OT's } \\
\text { recruited }\end{array}$} & \multicolumn{4}{|c|}{$\begin{array}{l}\text { Occupational therapy } \\
\text { participants }\end{array}$} & \multirow{2}{*}{$\begin{array}{l}\text { Response } \\
\text { rate }\end{array}$} & \multirow[t]{2}{*}{ Rating } \\
\hline & & VR** & MH*** & $\begin{array}{l}\text { VR** \& } \\
\text { MH*** }\end{array}$ & Total & & \\
\hline $\begin{array}{l}\text { Phase one } \\
\text { Descriptive } \\
\text { open-ended } \\
\text { questionnaire }\end{array}$ & 60 & 19 & 0 & 9 & 28 & $46.6 \%$ & Fair \\
\hline $\begin{array}{l}\text { Phase two } \\
\text { Focus Group }\end{array}$ & $18^{*}$ & $5 *$ & $2^{*}$ & $4^{*}$ & II* & $61.1 \%$ & Good \\
\hline $\begin{array}{l}\text { Phase three } \\
\text { Member } \\
\text { Checking }\end{array}$ & $11 *$ & $4 *$ & $2^{*}$ & $3 *$ & 9* & $81.8 \%$ & Good \\
\hline Total & 78 & 24 & 2 & 13 & 39 & $50 \%$ & Good \\
\hline \multicolumn{8}{|c|}{$\begin{array}{l}\text { *same participants } \\
\text { ** VR - vocational rehabilitation } \\
\text { ***MH - Mental Health }\end{array}$} \\
\hline
\end{tabular}

\section{Phase II}

Two focus group interviews were conducted with I I occupational therapists who had more than ten years' clinical experience. The focus group interview was semi-structured ${ }^{35,36}$, requiring the participants to answer a set of pre-determined questions ${ }^{35}$. The focus group interview guide was developed from the results of Phase I that needed further discussion, elaboration and clarification. The questions for the focus group were scrutinised by three senior lecturers (experts in qualitative studies) before they were used. See Box $2^{15}$ below for the focus group interview guide in Phase II. Open-ended questions encouraged participants' reflection on their day to day clinical practices while doing FCEs. Data saturation was reached after two focus group interviews.

\section{Phase III}

Member checking was done in Phase III where the results of the data obtained in the focus groups (Phase II) were shown and discussed with nine of the eleven participants from Phase II who were able to attend. This assisted with the elaboration and confirmation of the findings from Phase II.

\section{Data analysis}

In Phase I, the data were analysed using content analysis ${ }^{37}$ in which the views and perceptions of occupational therapists were grouped

\section{Box 2: Focus group interview guide ${ }^{15}$}

Work capacity: If you think about the role of the occupational therapist in determining work capacity what comes to mind?

Work incapacity: Which factors will you take into consideration to declare employees as unable to work?

Malingering: Do you sometimes find that employees suffering from a major depressive disorder pretend that they are ill in order to avoid returning to work?

Personality disorders: To what extent do you think an additional diagnosis will influence an employee's capacity and ability to-returnto-work?

Practices of occupational therapists: What do you perceive or view as a good occupational therapy practice in determining work capacity with employees suffering from a major depressive disorder?

Is it possible to give some specific criteria for a good occupational therapy practice?

Steps to determine work capacity: Occupational therapists use different steps to determine work capacity with employees suffering from major depressive disorder. How will you describe the steps that you think a competent occupational therapist should follow to perform a quality type of functional. according to themes and categories and their frequencies were counted. In Phase II, focus group transcriptions were compiled verbatim. Thematic analysis ${ }^{37,38}$ to compare and contrast similarities across the data was used and themes were formulated. The researchers and an external auditor independently analysed the data. On completion of both analyses, themes were renamed and discussed in order to reach agreement between the coders. All the themes and sub-themes were recorded for confirmation during member checking in Phase III.

\section{Measures to ensure trustworthiness}

The researchers ensured trustworthiness by constantly examining aspects of truth-value, rigour, integrity, applicability, consistency and neutrality in the research study ${ }^{35}$. The researchers ensured the application of various criterion strategies to ensure trustworthiness of the findings as suggested by Lincoln and Guba cited by Polit and $\mathrm{Beck}^{34}$. The researchers used member checking, on-going supervisor critique and peer examination to validate the findings. During member checking, the participants suggested amendments and clarifications of terms to the researchers. Peer examination was used with an external auditor to scrutinise data and confirm categories and themes and to view the entire project, including validity checks, to ensure the credibility of the final account ${ }^{34}$.

\section{FINDINGS}

\section{Participants}

The sample consisted of 39 participants in total, seven males and 32 females (Table $I$ above). The ages ranged between 26 and 60 years with a median age of 36 years. Most of the participants (60\%) worked in vocational rehabilitation settings. Twenty-seven percent $(27 \%)$ worked in a combined vocational rehabilitation and mental health setting and $13 \%$ in mental health settings only.

Sixty questionnaires (Phase I) were distributed as e-mails and posted to the participants. A response rate of $46.6 \%$ was obtained ${ }^{35}$. The response rate improved in Phase II and III to above $50 \%$.

\section{Themes}

The themes that emerged from the three phases of the study were the views and perceptions of occupational therapists' in determining FCEs of employees suffering from MDD. Three themes emerged as (I) occupational therapists' competencies in performing functional capacity evaluations; (2) the process of functional capacity evaluation itself, and (3) comprehensiveness of functional capacity evaluations.

Theme I: Occupational therapists' competencies in performing functional capacity evaluations

Functional capacity evaluations should be performed by qualified occupational therapists who regularly perform FCEs within their scope 
of practice. Occupational therapists' competencies were evinced in three categories, viz. (I) knowledge, (2) experience and (3) skills.

Occupational therapists' knowledge included knowledge of pathology (diagnostic and prognostic factors), guiding of occupational therapy theories, the occupational therapy process, the assessment process, legislation, the role of human resource practitioners, the economic climate and finally knowledge of the world of work. Two of the participants asserted that knowledge of MDD was essential:

... if you [occupational therapist] don't have an idea of the depressed client [employees]... you [therapist] will miss the point.... (Participant 4)

...the basic knowledge of the world of work is also valuable... Legislation, the world's economic climate, the role of human resource practitioners, travelling methods to work...prevocational skills needed for MDD employees to return to work.... (Participant 6)

The experience of the occupational therapist was found to be valuable. Participants viewed both clinical experience and rehabilitation experience as important;

...it is valuable to have worked with MDD clients (employees) prior to doing FCEs... (Participant 7)

During member checking, occupational therapy skills were considered essential while doing FCEs. Skills in the following areas were considered essential: therapeutic relationships, clinical reasoning, interview, functional capacity evaluation, negotiation and advocacy, communication and conflict resolution, observation, job analysis, assertiveness, diplomatic skills, both administrative and management skills, case management and research skills. Participants viewed FCEs as intensive assessments that required a wide range of competencies, as advised by one of the participants that:

Don't assess and say goodbye...you [the therapist] need to think clearly about the client [employee]...including the qualitative components...I mean the observations.... (Participant 10)

\section{Theme 2: The process of functional capacity evaluation} The FCE process should guide the occupational therapist in a systematic way. Participants indicated that the following aspects related to FCEs were important: (I) the occupational therapist must understand and interpret the reason for the referral clearly; (2) collect information about the employee's work ability, including the employee's job and work history, medical reports and work attendance; (3) obtain collateral information from the employee's family and employer (management and/or colleagues), referral sources or treating team; (4) the process must include an interview, a physical screening/assessment; psychosocial assessment and a work capacity evaluation using standardised measures and non-standardised assessments and a work visit if necessary. Based on the information gathered during this process, the occupational therapist must formulate a return to work decision and recommend whether the employee can return to work or not. One of the participants was of the opinion that:

...the process will be completed by making the decision of returning the clients [employee] to work... whether that is possible or not.... (Participant 3)

While the process of FCE encourages a logical step sequence, occupational therapists need to be flexible as the process is only a guideline. This observation concurs with that of the participant who remarked that:

... there is no exact procedure to follow in the field of functional capacity evaluation, flexibility is important... (Participant 10)

Theme 3: Comprehensive functional capacity evaluation Occupational therapists considered various factors to be critical for comprehensive FCEs. Important factors were (I) interviewing; (2) tools in the Occupational Therapy Department; (3) assessment of inappropriate illness behaviour, and (4) assessment of the employee's environment. A comprehensive FCE is objective, comprehensive, defendable and effective. One of the participants advised that:

The assessment must be comprehensive and you [occupational therapist] still have to apply decision making and clinical judgement while using standardised testing [measures].... (Participant 7)

The study participants unanimously agreed that the occupational therapist should have initial contact with the employee during a comprehensive, intensive, semi-structured interview that should last a maximum of two hours. If there is a need for further information, the occupational therapist might need to interview family and/or the employer.

The tools in the Occupational Therapy Department regarding suggested standardised measures by participants included: cognitive standardised measures such as the Rivermead Behavioural Memory Test (RBMT-3) ${ }^{39}$, the Modular Arrangement of Predetermined Time Standards (MODAPTS ${ }^{40}$, work samples for reading, writing, comprehension and basic mathematics, the Chessington Occupational Therapy Neurological Assessment Battery (COTNAB) ${ }^{41}$, the Valpar Component Work Samples 6 (VCWS 6) ${ }^{42}$, the Therapist's Portable Skills Assessment Laboratory (T/PAL) ${ }^{43}$, the Ross Test of Higher Cognitive Process ${ }^{44}$ and the Mini-Mental Status Examination (MMSE) ${ }^{45}$.

The tools in the Occupational Therapy Department further included the use of self-report questionnaires such as the Hospital Anxiety and Depression Scale (HADS) ${ }^{46}$, the Beck Depression Inventory $(\mathrm{BDI})^{47}$, quality of life scale ${ }^{48}$, interest checklist ${ }^{49}$, the Patient Health Questionnaire (PHQ-9 $)^{50,51}$ and the General Health Questionnaire $^{52,53}$. The suggested pain questionnaires, although not essential with employees suffering from MDD, were the Visual Analogue Scale $\mathrm{e}^{54,55}$ and the McGill Pain Questionnaire ${ }^{55,56}$.

The physical capacity measures, considered relevant by the study participants with employees suffering from MDD, were MODAPTS work samples for climbing stairs and lifting ${ }^{40}$, and VCWS $9^{57}$ and VCWS $201^{58}$. The recommended standardised measure to assess participation of employees doing activities of daily living (ADL) is the Assessment of Motor and Process Skills (AMPS) ${ }^{59,60}$.

The following non-standardised assessments were found to be helpful during the FCEs of employees suffering from MDD: Use of a variety of activities, participation in task-centred occupational therapy groups, and clinical observation and assessment of the employee's environment. One of the participants reported that:

The more the occupational therapist is unsure of what they are doing [the more] they fall into the trap of standardised tools and ignore the observations.... (Participant 3)

Participants viewed the assessment of inappropriate illness behaviour as critical, including familiarity with complex personality disorders. It was further recommended that for the comprehensive assessment to be objective, occupational therapists needed to triangulate their findings, observations and collateral information for consistencies. One of the participants stated that they were to:

...take inconsistencies in effort and suboptimal effort in performance seriously...find out why.... (Participant II).

The need to evaluate the employees in their natural physical environment such as work and/or home in order to assess their interpersonal relationships and other social environmental factors emerged from the observations of the participants. One of the participants added that:

...know the job...know the environment...and interpersonal relationships at work.... (Participant 9)

\section{DISCUSSION}

Occupational therapists perceive competency to be valuable while performing FCEs with employees suffering from MDD. Competency includes the occupational therapists' knowledge, experience and skill. Occupational therapists also believe that their co-workers should have wisdom, maturity and expert experience. These traits 
will enable analytical thinking, open-mindedness, flexibility and self-regulation during the FCE process. More experienced evaluators have abilities that extend beyond most test batteries ${ }^{61}$. These evaluators engage in reflective practice that promotes conscious analysis in the decision-making process, and where existing knowledge is analysed to generate new knowledge and ideas ${ }^{28}$. Occupational therapy practice is characterised by continuous growth of knowledge through reflective practices that develop and improve clinical skills ${ }^{28}$. Occupational therapists have a moral responsibility to share their knowledge, augment existing knowledge and to lead in improved quality of service in occupational therapy practices.

Occupational therapists were of the opinion that FCEs include knowing the specific mental functions and/or physical abilities that need to be assessed. They should also be aware of inappropriate illness behaviour that should be taken into cognisance during their interpretation of the assessment results. They further stated that FCEs of employees suffering from MDD required comprehensive psychiatric evaluation, as stated in DSM $-5^{19}$, which includes specific mental functions (thought processes, cognition, mood and affect, insight, psychomotor activity and visual perceptual abilities) as well as global mental functions (orientation, sleeping patterns, energy levels and drive and endurance $)^{62}$, all of which are found to be helpful in completing the assessment.

While most occupational therapists (in this study) believed that FCEs should follow a logical process, Roley et $\mathrm{al}^{63}$ warned that the process does not always occur in a sequential step by step fashion. The process is dynamic and allows occupational therapists to practice with an ongoing focus on outcomes while constantly changing their overall plan in order to accommodate changes along the way. The interview, most participants observed, should guide the occupational therapist's choice of appropriate standardised measures and non-standardised assessments to be used with the employee. This agrees with the findings of Rouleau, Dion and Korner-Bitensky ${ }^{10}$, who reported that occupational therapists in mental health use interviews, observations and standardised measures for assessment. South African occupational therapists (in this study) believe that the FCEs is a lengthy process that requires an occupational therapist's competency in the use of standardised measurement tools and non-standardised assessments, which enables him or her to clearly observe the employee's capacity and assists in reducing possible risks in a workplace. Occupational therapists should be able to triangulate assessment finding ${ }^{21,28}$ from standardised measurements, non-standardised assessments and application of clinical reasoning in order to formulate objective, defensible and justifiable decisions about the employee's future return-to-work potential. Although non-standardised assessments were found to be effective in this study, the issue about lack of evidence and publications about their validity should be noted.

Occupational therapists need to think continuously (employing both analytical and abstract thinking) and to apply their clinical reasoning, decision making, professional judgement and the guiding occupational therapy conceptual framework throughout the evaluation process in order to make a fair decision about the employee's future work ability. Occupational therapists (in this study) agreed that assessment tools do not evaluate the employee's "physical and social environment" ${ }^{2: 528}$. Occupational therapists (in this study) also advised that some employees should be assessed at their workplace or at home as part of the FCE in order to have an understanding of both the physical and social environmental factors (since a specific criticism of the FCE is its disregard of environmental factors) and which may present a significant barrier to an employee's return to work. Smith and Brintnell ${ }^{29}$ advised that the evaluation should encompass the work capacity of the employee in regard to his or her specific job or accepted occupational standard.

\section{CONCLUSION}

The views and perceptions of occupational therapists in performing FCEs with employees suffering from MDD is to formulate a return- to-work decision. The return-to-work decision is formulated by the FCE process that involves interviewing, assessment (physical and psychosocial) and work capacity evaluation for employees suffering from MDD. FCE requires using standardised measurement tools, non-standardised assessments and clinical reasoning.

Occupational therapists in South Africa view FCEs as intensive. The process requires numerous assessments ranging from psychometric evaluations to physical evaluations of the work place. Participants were thus of the opinion that only qualified, skilled and experienced occupational therapists should be able to conduct FCEs provided they had both adequate facilities and knowledge of the illness. Furthermore, the researchers hoped that this study might assist in enhancing the future integrity of occupational therapy as a profession in conducting FCEs.

\section{LIMITATIONS}

The views and perceptions of other health professionals and occupational therapists in other provinces were not explored despite their valuable contribution to FCEs.

\section{ACKNOWLEDGEMENTS}

The authors would like to thank the participants who willingly participated in the research study and reflected on their day to day clinical practice and experience as occupational therapists. The authors gratefully acknowledge the time commitment, assistance, suggestions and comments during this research journey of $\mathrm{Dr}$ Marianne de Beer and Prof Daleen Casteleijn. Many thanks to Mrs Anna Lesunyane and Mpho Monyatsi for their encouragement and reading of this article.

\section{REFERENCES}

I. Reddy MS. Depression: The Disorder and the Burden. Indian Journal of Psychological Medicine. 2010; 32(I): I-2. DOI: 10.4103/02537176.70510 .

2. Stander MP, Korb FA, de Necker M, de Beer JC, Miller-Janson HE, Moont R. Depression and the Impact on Productivity in the Workplace: Findings from a South African Survey on Depression in the Workplace. Journal of Depression and Anxiety. 2016; S2: I-8. DOI: 10.4172/2167-1044.S2-012.

3. Welthagen C, Els C. Depressed, not depressed or unsure: prevalence and the relation to well-being across sectors in South Africa. SA Journal of Industrial Psychology. 2012; 38: 57-69.

4. Lerner D, Adler DA, Chang H, Lapitsky L, Hood MY, Perissinotto C, et al. Unemployment, Job Retention, and Productivity Loss Among Employees With Depression. Psychiatric Services. 2004; 55(I2): I37|-8.

5. Chen J. Functional Capacity Evaluation and Disability. The IOWA orthopaedic Journal. 2007; 27:121-127. [Cited 2007/06/24 at I0h45]. Available from: http://www. Uihealthcare.com/depts/med/ orthopaedic surgery/ioj/2007/chenfce.pdf.

6. Rytsala HJ, Melartin TK, Leskella US, Sokero PT, Lestela-Mielonen PS, Isometsa ET. Functional and Work Disability in major depressive disorder. The Journal of Nervous and Mental Disease. 2005 Mar; 193(3): 189-195

7. Managh MF, Cook JV. The Use of standardized Assessment in occupational therapy: The BaFPE-R as an Example. American Journal of Occupational Therapy. 1993; 47(10): 877-884.

8. Gibson L, Strong J. A conceptual framework of functional capacity evaluation for occupational therapy in work rehabilitation. Australian Journal of Occupational Therapy. 2003; 50: 64-7I.

9. Kirsh B, Cockburn L. The Canadian occupational performance measure: A tool for recovery-based practice. Psychiatric Rehabilitation Journal. 2009; 32(3): I7I-6.

10. Rouleau S, Dion K, Korner-Bitensky N. Assessment practices of Canadian occupational therapists working with adults with mental disorders: Les pratiques d'évaluation des ergothérapeutes canadiens travaillant auprès d'adultes atteints de troubles mentaux. Canadian Journal of Occupational Therapy. 2015; 82(3): 181-93.

II. Fuller K. The Effectiveness of Occupational Performance Outcome Measures within Mental Health Practice. The British Journal of Occupational Therapy. 201 I; 74(8): 399-405. 
12. Gutman SA, Raphael-Greenfield El. Five years of mental health research in the American journal of occupational therapy, 2009-20I3. American Journal of Occupational Therapy. 20I4; 68(I): e2I-36.

13. Lenze EJ, Rogers JC, Martire LM. The Association of Late-Life Depression and Anxiety with Physical Disability. American Journal of Geriatric Psychiatry. 2000; 9(2): I I 3- I35.

14. Bhagwanjee A, Parekh A, Paruk Z, Petersen I, Subedar H. Prevalence of minor psychiatric disorders in an adult African rural community in South Africa. Psychological Medicine. 1998; 28(05): II37-47.

15. Dzator J. Hard Times and Common Mental Health Disorders in Developing Countries: Insights from Urban Ghana. The Journal of Behavioral Health Services \& Research. 2013; 40(I): 7I-87.

16. Ramano E, Buys T, de Beer M. Formulating a return-to-work decision for employees with major depressive disorders: occupational therapists' experiences. African journal of primary health care and family medicine. 2016; 8(2): I-5

17. Salkever DS, Goldman H, Purushothaman M, Shinogle J. Disability Management, Employee Health and Fringe benefits, and Long-TermDisability Claims for Mental Disorders: An Empirical Exploration. The Milbank Quarterly. 2000; 78(I): 79-II3.

18. Joska J. The unhappy or depressed patient. In: Baumann SE. Primary Health Care Psychiatry- A practical guide for Southern Africa. South Africa: Juta \& Co, Ltd; 2007: 423-445.

19. American Psychiatric Association. Diagnostic and Statistical Manual of Mental Disorders DSM-5. United State of America: American Psychiatric Publishing; 2013: I55-188.

20. Kielhofner G. A Model of Human Occupation Theory and Application. 4th Ed. Baltimore: Williams \& Wilkins; 2008.

21. Deen M, Gibson L, Strong J. A survey of occupational therapy in Australia work practice. Work. 2002; 19: 219-230.

22. Dube AK. The role and effectiveness of the disability legislation in South Africa. Disability Knowledge and Research. Mar; 2005.

23. Labour Relations Act. Republic of South Africa Government Gazette, Notice 66 of 1995. Vol 366: No. 1686I. Pretoria: Government Printers. 13 Dec; 1995.

24. Employment Equity Act. Republic of South Africa Government Gazette, Notice 55 of 1998. Vol 400: No 1323. Pretoria: Government Printers. October; 1998.

25. Menard M, Gorman D. Work capacity evaluation. New Zealand Medical Journal. 2000; II 3 (III5): 335-337.

26. Innes E, Straker L. Attributes of excellence in work-related assessments. Work. 2003; 20: 63-76.

27. Legge J, Burgess-Limerick R. Reliability of the Job Fit System PreEmployment Functional Assessment Tool. Work. 2007; 28: 299-3 I 2.

28. Laver-Fawcett AJ. Principles of Assessment and Outcome Measurements for Occupational therapists' and Physiotherapists: Theory, Skills and Application. Chichester: John Wiley and Sons Ltd; 2007.

29. Smith JI, Brintnell ES. Functional Capacity Evaluation of Individuals with Acquired Brain Injury. Toronto ABI Network Conference; Nov; 2004.

30. Jones $\mathrm{T}$, Kumar $\mathrm{S}$. Functional capacity evaluation of manual materials handlers: a review. Disability and Rehabilitation. 2003; 25(4-5): I79-191.

31. Ross J. Occupational Therapy and Vocational Rehabilitation. London: John Wiley \& Sons Ltd; 2010.

32. Holma IAK, Holma KM, Melartin TK, Rytsälä HJ, Isometsä ET. A 5-year prospective study of predictors for disability pension among patients with major depressive disorder. Acta Psychiatrica Scandinavica. 2012; I25(4): 325-34.

33. Rytsälä HJ, Melartin TK, Leskelä US, Sokero TP, Lestelä-Mielonen PS, Isometsä ET. Predictors of long-term work disability in Major Depressive Disorder: a prospective study. Acta Psychiatrica Scandinavica. 2007; II5(3): 206-13.

34. De Voss AS, Strydom H, Fouche CB, Delport CSL. Research at grass root for the social science and human service professions. 4th Ed. Van Schaik Publications; $201 \mathrm{I}$.

35. Polit DF, Beck CT. Essential of Nursing Research: Appraising Evidence for Nursing Practice. 7thEd. Philadelphia: Wolters Kluwer Health Lippincott Williams \& Wilkins; 2010.

36. Brink $H$, van der Walt, van Rensburg G. Fundamentals of Research Methodology for Health Professionals. 2nd Ed. Cape Town: Juta \& Co; 2006.

37. Nieuwenhuis J. Qualitative research designs and data gathering. In:
Maree K. First Steps in Research. RSA: Van Schaik Publishers; 2007: 70-92.

38. Bergman MM. Hermeneutic content analysis: Textual and audiovisual analysis within a mixed method framework. In: Tashakkori A, Teddlie C. SAGE handbook of mixed methods in social and behavioural research. 2nd Ed. USA: SAGE publications Inc; 2010: 379-396.

39. Wilson BA, Greenfield E, Clare L, Baddeley A, Cockburn J, Watson P, Tate R, Sopena S, Nannery R, Crawford J. Rivermead Behavioural Memory Test-Third Edition (RBMT-3). UK: Pearson Education Ltd; 2008.

40. Carey P, Farrell J, Hui M, Sullivan B. Heydes Modapts book. Australia: Heyde Dynamics Pty Ltd; 200I. ISBN 0-9596597-5-7.

4I. Stanley M, Butterfield J, Williams C. Chessington Occupational Therapy Neurological Assessment Battery: Comparison of performance of people aged $50-65$ years with people aged 66 years and over. Australian Occupational Therapy Journal. 20 I 0; 42(2): 55-65.

42. Valpar International Corporation. Manual for Valpar Component Work Sample 6: Independent Problem Solving. Virginia: Busic and Scott Evaluation Systems; 2009.

43. Valpar International Cooperation. T/PAL Manual for The Therapist's Portable Skills Assessment Module. USA: Piney Mountain Press Inc.; 2002.

44. Ross JD. Ross Test of Higher Cognitive Process. Novato, Calif: Academic Therapy Publications; 1976.

45. Folstein M, Folstein SE, McHugh PR. Mini-Mental State a Practical Method for Grading the Cognitive State of Patients for Clinicians. Journal of Psychiatric Research. 1975; I2(3): 189-198.

46. Zigmond AS, Snaith RP. The Hospital Anxiety and Depression Scale. Acta Psychiatrica Scandinavica. 1983; 57(6): 36I-370. DOI: I0.1 III/j.1600-0447.1983.tb097/6.x

47. Beck AT, Steer RA, Garbin MG. Psychometric properties of the Beck Depression Inventory. Twenty-Five years of evaluation. Clinical Psychology Review. 1988; 8(I):77-100.

48. Bigelow DA, Olson MM, Smoyer S, Stewart L. Quality of life questionnaire: Respondent self-report version (Interview Schedule). Western Mental Health Research Centre. Oregon Health Science University, Portland, Oregon; 1991.

49. Klyczek JP, Bauer-Yox N, Fiedler RC. The Interest Checklist: A Factor Analysis. American Journal of Occupational Therapy. 1997; 5 I (10): 815-823.

50. Kroenke K, Spitzer RL, Williams JBW. The PHQ-9: validity of a Brief Depression Severity Measure. Journal of General Internal Medicine. 200I; 16(9): 606-6I3. Doi: 10.1046/j.1525.200I.0160 09606.x.

5I. Ramano EM, de Beer M, Roos JL, Becker PJ. A comparison of two occupational therapy group programme on the functioning of patients with major depressive disorders. Minerva Psichiatrica. 2017; 58(3): 125-134.

52. Montazeri A, Harirchi AM, Garmaroudi G, Ebadi M, Fateh A. The 12-item General Health Questionnaire (GHQ-12): translation and validation study of the Iranian version. Health Quality of Life Outcomes. 2003; I (66): I-4.

53. Sterling M. General Health Questionnaire 28. Journal of Physiotherapy. 201 I; 57(4): 259.

54. Williams VSL, Morlock RJ, Feltner D. Psychometric evaluation of a visual analog scale for the assessment of anxiety. Health Quality of Life Outcomes. 2010; 8(57): I-8.

55. Hawker GA, Mian S, Kendzerska T, French M. Measures of Adult Pain. Arthritis Care and Research. 20I I; 63(SI I): S240-S252.

56. Melzack R. The McGill Pain Questionnaire: Major properties and scoring methods. The Journal of the International Association for the Study of Pain. 1975; I(3): 277-299. DOI:10.1016/03043959(75)90044-5.

57. Valpar International Cooperation. Manual for Valpar Component Work Sample 9: Whole Body Range Motion. Tucson, Arizona: Valpar International Corporation; 2003.

58. Valpar International Cooperation. Manual for Valpar Component Work Sample 20 I: Physical Capacities and Mobility. Virginia: Busic and Scott Evaluation Systems; 2010.

59. Fisher AG. Assessment of Motor and Process Skills Vol 2. User Manual 6th ed. Fort Collins, CO: Three Star Press; 2006b.

60. Merritt BK. Validity of using the Assessment of Motor and Process 
Skills to determine the need for assistance. American Journal of Occupational Therapy. 20I I; 65(6): 643-650.

6I. Jahn WT, Cupon LN, Steinbaugh JH. Functional and Work Capacity Evaluation issues. Journal of Chiropractic Medicine. 2004; 3(I): I-5.

62. American Occupational Therapy Association. Occupational Therapy Practice Framework: Domain and Process. 3rd Ed. American Journal of Occupational Therapy. 20I4; 68 (I): SI-S48.

63. Roley SS, DeLany JV, Barrows CJ, Brownrigg S, Honaker D, Sava DI, Talley V, Voelkerding K, Amini DA, Smith E, Toto P, King S. Occupational Therapy Practice Framework: Domain and Process. 2nd Ed. American Journal of Occupational Therapy. 2008 Nov/Dec; 62(6): 625-76.

\section{Corresponding author}

\section{Enos M Ramano}

E-mail: eramano@telkomsa.net 